American Journal of Economics and Business Administration 3 (2): 277-281, 2011

ISSN 1945-5488

(C) 2010 Science Publications

\title{
Performance Evaluation a Teaching Hospital Affiliated to Tehran University of Medical Sciences Based on Baldrige Excellence Model
}

\author{
${ }^{1}$ Fereshteh Farzianpour, ${ }^{2}$ Sara Aghababa, ${ }^{3}$ Bahram Delgoshaei and ${ }^{4}$ Marjan Haghgoo \\ ${ }^{1}$ Department of Health management and Economics, \\ School Public Health Tehran University of Medical Sciences, Tehran, Iran \\ ${ }^{2}$ Department of Health Services Administration, Islamic Azad University, \\ Science and Research Branch, Young Researchers Club, Tehran, Iran \\ ${ }^{3}$ Department of Health Services Administration, School of Management and Medical Information, \\ Iran University of Medical Sciences, Tehran, Iran \\ ${ }^{4}$ Department of Health Services Administration, Tehran University of Medical Sciences, Tehran, Iran
}

\begin{abstract}
Problem statement: Today, organizations are willing to achieve quality as a source of competitive advantage. Therefore, their performance evaluation and quality improvement is essential. One of the international models in this field is Baldrige health care model. Approach: The study aimed to evaluate Performance Evaluation a teaching Hospital Affiliated to Tehran University of Medical Sciences Based on Baldrige Excellence Model. Performance was evaluated by two types Baldrige questionnaire (i.e., process and result criteria). Six process criteria (Leadership; Strategic Planning; Focus on Patients, Other Customers and Markets; Measurement, Analysis and Knowledge Management; Workforce Focus; and Process Management) with 12 sub-criteria, were evaluated based on four factors of Approach, Deployment, Learning and Integration. Results criteria with six subcriteria were evaluated based on four factors of performance level, rate and breath of performance improvement, comparative and benchmark data and relevance of evaluation result scales. Results: The teaching hospital obtained 145/21 scores (26/40 percent) out of a total of 550 points in process criteria and 90/37 scores (20/08 percent) out of a total of 450 points in result criteria. Studied hospital obtained the highest score in Measurement, Analysis and Knowledge Management 28/1 scores (31/22 percent). In Sum, the hospital obtained 235/58 scores (23/55 percent) out of 1000 points. Conclusion: Scores obtained by hospital showed the first level of excellence. The outcome of this study clearly indicates that Baldrige model criteria act as a powerful tool to analyze the quality performance of the hospitals. The researchers attempted to create a common language and a roadmap in order to follow the path of excellence in health care organizations in Iran.
\end{abstract}

Key words: Performance evaluation, focus criterion, process management, knowledge management, ISO certification, systematic approaches, strategic planning

\section{INTRODUCTION}

Performance evaluation system which uses a quantified indicator system to measure and evaluate the performance in every organization in order to aware that rate of quality and utility ,especially in complicated and dynamic environment.

Performance evaluation in health care industry is essential in order to determine the situation and also to improve and promote the organization (Miller et al., 2009). The most frequently used international model in the world is MalcolmBaldrige Model (Baldrige National Quality Program, 2011).US organizations competing for the Malcolm Baldrige National Quality Award are evaluated on seven criteria:leadership;strategic planning; customer focus; process management; and results(Chase,R.B,R.F.Jacobs and N.J.Aquilano,2008).

Manufacturing organizations seeking European ISO 9000 certification must meet eight broad quality management principles: customer focus, leadership, involvement of people, process approach and system approach to management. Continual improvement, factual approach to decision making and mutually beneficial supplier (ISO, 2009). International organization for standardization).Previous studies

Corresponding Author: Fereshteh Farzianpour, Department of Health management and Economics, School Public Health Tehran University of Medical Sciences, Tehran, Iran 
showed that the quality of health service has a major influence on the patient satisfaction and behaviors such as honesty and reputation of the health organization (Suifan, 2010). As health care organizations are becoming more and more complex, old models of quality assurance, relying on provider-based preset standards are insufficient to solving quality problems (Manjunath et al., 2007).

Although many approaches to improve quality in health care organizations have been implemented along the past century (Ramsaran-Fowdar, 2008), so performance measurement is not easy, particularly in health and public services (Crescent, 2008). On the other hand, many national quality awards originated after 1990 and some are still at that stage of accumulating learned experiences through assessing organizations on their processes. All the awards represent organizational efforts to enhance international reputation in an increasingly competitive environment in multi-national organizations (Xiang et al., 2010).

Health care organizations such as hospitals in Iran need major changes like in any other developing nations and making sincere efforts to establish quality management practices. Meanwhile, Islamic Republic of Iran Fourth Plan on economic, Social and cultural Development emphasizes on adaptive local quality evaluation system with international standards (paragraph2, Article 39). also in the first paragraph at Article 88 of this plan, ministry of health being obliged to promote quality of health and excellence in clinical services, improve productivity and efficient use of country health facilities, must codify monitoring and evaluation standards and indicators to promote quality of services and improve hospital ranking system based on clinical excellence models.

As well as the Baldrige Health Care criteria are well known and widely used by hospitals for selfassessment purposes (West, 2001), the researchers select/choose this model in order to evaluate the level of performance in the Teaching Hospital Affiliated to Tehran University of Medical Sciences based on 20092010 version in 7 criterion and 18 sub criterion.

\section{MATERIALS AND METHODS}

This cross sectional study implemented in a teaching hospital. No sampling was carried out and Data were collected and compare with response of 2009-2010 version of the model questionnaire.

Question items from the criteria were used as a tool to evaluate quality of the Hospital. Data collection included visiting the department, interviews, focus group discussion meetings with prior appointment and necessary permissions. Relevant documents (such as brochures hospital, magazines, documents, policy statements) were examined with the permission of the managers.

The scoring of responses to Criteria Items and Award applicant feedback were based on two evaluation dimensions: Process and Results.

The four factors used to evaluate process (Leadership, Strategic Planning, Customer Focus, Measurement, Analysis and Knowledge Management, Workforce Focus, Process Management) were Approach, Deployment, Learning and Integration with 19 questionnaires. Higher scores reflect greater achievement, demonstrated by broader deployment, significant organizational learning and increased integration. In addition the four factors used to evaluate results were Levels, Trends, Comparisons and Integration with 6 questionnaires. Higher scores reflect better trends and levels of performance, stronger comparative performance and broader coverage and integration with the requirements of the organization or mission. As regards, 1 questionnaire about organizational Profile didn't used in scoring system.

In order to score the questionnaire total ranging from 0-1000 were computed $(0-250,251-350,451-55-$, 551-650, 651-750, 651-750, 751-875 and 876-1000). On the other hand scores of each criterion classified in six category: $0-5 \%, 10-25 \%, 30-45 \%, 50-65 \%, 70-$ $85 \%$ and $90-100 \%$. In order to Data Analysis, we used SPSS software.

\section{RESULTS}

The averaged of results for each sub criteria and the Baldrige points are given in Table 1.

Research results indicated that the overall average score obtained for the hospital in the study was estimated to be 235.85 out of total 1000 score (145.21 out of 550 scores from process criteria and 90.37 out of 450 scores from results criteria).

The teaching hospital obtained the highest score (31/22 percent) in Measurement, Analysis and Knowledge Management and the lowest score (20.08 percent) in results.

As seen from Table 1 overall "leadership" criterion points are low (26.55 out of 120 points in model).

As shown in Table 1, performance evaluation of studied hospital shown 31.87 out of 120 point in leadership criterion, 17.56 out of 85 point in Strategic Planning criterion, 21.75 out of 85 point in Customer Focus criterion, 28.1 out of 90 point in Measurement, Analysis and Knowledge Management criterion, 22.06 out of 85 point in Workforce Focus criterion, 23.87 out of 85 point in Process Management criterion, 90.37 out of 450 point in Results criterion. 
Am. J. of Economics and Business Administration 3 (2): 277-281, 2011

Table 1: Showing Baldrige points for the case hospital based on 2009-2010 version of model

\begin{tabular}{lcc}
\hline Baldrige criteria category & $\begin{array}{l}\text { Baldrige points } \\
\text { for case hospital }\end{array}$ & $\begin{array}{l}\text { Maximum } \\
\text { Baldrige points }\end{array}$ \\
\hline Leadership & 31.87 & 120 \\
Senior leadership & 17.50 & 70 \\
Governance and Societal & 14.37 & 50 \\
Responsibilities & & \\
Strategic planning & 20.20 & 85 \\
Strategy development & 9.40 & 40 \\
Strategy deployment & 10.80 & 45 \\
Customer focus & 21.75 & 85 \\
Customer engagement & 10.50 & 45 \\
Voice of the customer & 11.25 & 45 \\
measurement, analysis and & 28.10 & 90 \\
knowledge management & & \\
Measurement, analysis and & 13.50 & 45 \\
improvement of & & \\
organizational performance & & \\
Management of information, & 14.60 & 45 \\
knowledge and information & & \\
technology & & \\
Workforce focus & 22.06 & 85 \\
Workforce engagement & 9.56 & 45 \\
Workforce environment & 12.50 & 40 \\
Process management & 23.87 & 85 \\
Work systems & 11.37 & 35 \\
Work processes & 12.50 & 50 \\
Results & 90.37 & 450 \\
Health care outcomes & 21.25 & 100 \\
Customer-focused outcomes & 14.00 & 70 \\
Financial and market outcomes & 17.50 & 70 \\
Workforce-focused outcomes & 12.25 & 70 \\
Process effectiveness outcomes & 12.25 & 70 \\
Leadership outcomes & 13.12 & 70 \\
Total points & 235.58 & \\
\hline & & \\
\hline
\end{tabular}

\section{DISCUSSION}

The highest share of health care services is provided by organizations affiliated with universities of medical sciences acting directly under Ministry of Health (Mehrabi et al., 2008).

According to the obtained scores in the sina hospital in "leadership" criterion, senior leaders are beginning to systematically increase awareness of organizational concerns. Major deployment gaps exist. Decision making remains generally reactive. Senior leaders set and deploy short- and long-term goals. Some two-way communication is present. There is some improvement group involvement. There may be focus on ethical and legal practice issues.

Badri et al. (2006) the analysis of the case hospital supports that committed leadership is a driver for management accountability and creation of environment for empowerment and organizational agility. Also leadership has influence on the other criteria. Jayamaha et al. (2008) expressed that their result was the development of Baldrige based model that demonstrated the relationship between executive leadership and the Baldrige criteria. In addition, Aghababa et al. (2010) declared that in Hazrat Rasoul hospital in Iran, leadership, strategic planning, customer focus, workforce focus; and in Firouzgar hospital, leadership, customer focus, measurement, analysis and knowledge management and workforce focus, was are in the early systematic approaches. In this research leadership; process management; and measure, analysis and knowledge management are in the early systematic approaches. Based on "strategic planning" criterion, action plans have been developed to address a few strategic objectives, but resource allocation strategies are not effective. Some evidence of an action planning process is evident, with critical success factors identified. The approach is still more reactive to organizational crisis than preventive. There are major gaps in deployment.

Processes are not evaluated for improvement and alignment within the organization is not yet a planned activity.

Strategic planning as a promoter factor in his model of total quality management. On the other hand, Meyer and collier expressed that development and deployment of strategies is essential for health care organizations.

According to the "customer focus criterion", Collection and analysis of patient complaints and trends are systematic. Current and former patient information has been gathered and analyzed. Key patient requirements and preferences have been identified. There is a focus on building relationships and partnerships. But the hospital still has major gaps in deployment of processes and information, which inhibit progress toward goals.

Warwood and Antony (2003) have also been considered customer-focused processes contribute to the successful implementation of total quality management in their simple, semi-prescriptive selfassessment model.

About "measurement, analysis and knowledge management" criterion, processes are in place to manage dissemination of relevant information to customers, staff, suppliers and partners. Also responsive approaches are in early stages of deployment. Data are collected and tracked on the following organizational performance indicators: customer satisfaction, finance, human resource and operations.

In the research of Maleki et al. (2007) the emergency room of the studied hospital was in the second level of excellence. Also in this teaching hospital this criterion stands in the second level of excellence. It does show that health care organizations in Iran had less improvement in excellence model and 
they are in the first steps. In addition, Nabilou (2003) introduced information and analysis as a criterion of his model in Iran.

In "workforce focus" criterion, effective employee feedback data for some staff are available.

Staff satisfaction issues have been identified. The beginning of a systematic approach is in the early stages of deployment. Leaders recognize success comes from staff. But organization is still in the early stages of reacting to staff issues instead of planning and prevention. Training has been made available and aligned to strategic and staff development plans. Educational levels and job diversity are considered.

The results represent low and medium level of workforce corporation in performance. So the result was compatible with our study. Based on "process management" criterion a systematic approach to standard processes has begun.

Approaches are at the beginning stages of creating value added processes for the organization.

All key processes are identified and mapped. Opportunities for improvement have been assessed.

Early stages of deployment exist in most areas. Also awareness of new technologies is incorporated into appropriate or key support processes. So there is some cross departmental procedural sharing.

The hospital Manjunath et al. (2007) study has gotten ISO certification ISO certification. Hence in our research and Manjunath et al. (2007) study the score of process management was acceptable. But that does not address the people issues specifically employee motivation, leadership style, social concerns and what should be improved in order to gain a competitive position. So the Baldrige health care criteria would provide a good framework to analyze quality management practices in the case hospital that has obtained ISO certification and strives for continuous improvement based on TQM principles including committed leadership, customer focus and satisfaction, process improvement, service design, human resource management and social responsibility.

According to "results" criterion there are still few, if any, comparative data and trending data are over a brief period of time. Performance is beginning to improve due to focused activity within the hospital. There was few benchmarking on community perceptions and governance issues.

Many important organizational measures were missing and few Key performance outcomes are bbfgdfds established.

In this context, gholi pour and akhavan claim that results criterion is the most intentional factor of weaknesses toward excellence in Iranian organizations.
In addition, salarian declared that in order to improve the effectiveness and efficiency of hospitals attention of performance indicators are inevitable.

\section{CONCLUSION}

Although the hospital has been quite successful in moving forward from ISO certification, but the obtained score is judged to be performing at the first level of excellence. Using the Baldrige model aligns leaders, provides focus to organizational priorities and gives an outside perspective measured against other similar high performing organizations.

According to the steps toward mature processes, strategic planning, customer focus and workforce focus are in the stage of reacting to the problems. Operations are characterized by activities rather than by processes and they are largely responsive to immediate needs or problems. Goals are poorly defined. On the other hand leadership, process management and measure, analysis and knowledge management are in the stage of early systematic approaches.

The hospital is at the beginning stages of conducting operations by processes with repeatability, evaluation and improvement and some early coordination among organizational units. Strategy and quantitative goals are being defined.

Scores obtained by studied hospital showed the first level of excellence. This evaluation was the first step in excellence path in the application of 2009-2010 version of Baldrige model. The researcher attempted to create a common language and a roadmap in order to follow the path of excellence in health care organizations. It seems that the continuation of selfassessment plays an important role in the improvement of the scores.

\section{REFERENCES}

Aghababa, S., M.R. Maleki and M. Mortazavi, 2010. Leadership evaluation of emergency department of general -teaching hospital in iran university of medical science and health services based on baldrige excellence model: A short report. J. Rafsanjan Univ. Med. Sci. Health Services, 9: 59-64.

Badri, M.A., H. Selim, K. Alshare, E.E. Gardon and H. Younis et al., 2006. The baldrige education criteria for performance excellence framework: Empirical test and validation. Int. J. Qual. Reliabil. Manage., 23: 1118-1157. DOI: 10.1108/02656710610704249

Baldrige National Quality Program, 2011. Health Care Criteria for Performance Excellence. The National Institute of Standards and Technology. http://www.nist.gov/baldrige/publications/hc_criter ia.cfm 
Crescent, J.R., 2008.Annual report. Jordan Red Crescent. Amman. http://www.annualreports.com/Hosted Data/Annual Reports/PDF Archive/crfn2008.pdf

ISO, 2009. International organization for standardization. http://webstore.ansi.org/SdoInfo.aspx?sdoid=39

Jayamaha, N.P., N.P. Grigg and R.S. Mann, 2008. Empirical validity of baldrige criteria: New Zealand evidence. Int. J. Quality Reliabi. Manage., 25: 477-493. DOI: 10.1108/02656710810873880

Maleki, M., A. Nasiripour and S. Aghababa, 2007. Knowledge management of emergency department in rasul akram hospital based on baldrige excellence model in 2007. Health Infor. Manage., 4: 1386.

Manjunath, U., B.A. Metri and S. Ramachandran, 2007. Quality management in a healthcare organisation: A case of South Indian hospital. TQM Magazine, 19: 129-139. DOI: 10.1108/09544780710729971

Mehrabi, F., A. Nasiripour and B. Delgoshaei, 2008. Customer focus level following implementation of quality improvement model in Tehran social security hospitals. Int. J. Health Care Qual. Ass., 21: 562-568. PMID: 19055266

Miller, W.J., A.T. Sumner and R.H. Deane, 2009. Assessment of quality management practices within the healthcare industry. Am. J. Econ. Bus. Admin., 1: 105-113. DOI: 10.3844/ajebasp.2009.105.113
Nabilou, B., 2003. A Comparative Study of organizations' excellence models in the health system of selected countries and suggesting a model for Iran. [Thesis for Ph.D] Tehran: Iran University of Medical Sciences, School of Medical Information Management. http://journals.mui.ac.ir/index.php/him1/article/vie wFile/2605/1020

Ramsaran-Fowdar, R.R.R., 2008. The relative importance of service dimensions in a healthcare setting. Int. J. Health Care Quality Assur., 21: 104-124. DOI: $10.1108 / 09526860810841192$

Suifan, T.S., 2010. Quality of health services provided to Iraqis at Jordan red crescent health centers. J. Soc. Sci., 6: 170-178. DOI: 10.3844/jssp.2006.170.178

Warwood, S. and J. Antony, 2003. A simple, semiprescriptive self-assessment model for TQM. Quality Assurance, 10: 67-81.

West, E., 2001. Management matters: The link between hospital organisation and quality of patient care. Qual. Health Care, 10: 40-48. DOI: 10.1136/qhc.10.1.40

Xiang, J.Y., Z. He, Y.H. Suh, J.Y. Moon and Y.F. Liu, 2010. An empirical investigation of the China quality award causal Model. Asian J. quality, 11: 49-68. DOI: $10.1108 / 15982681011051822$ 